\title{
Organization and management of mobility of building production and its distinctive features
}

\author{
Larisa Prykina ${ }^{1, *}$ \\ ${ }^{1}$ Moscow State University of Civil Engineering, 129337, 26, Yaroslavskoye Shosse, Moscow, Russia
}

\begin{abstract}
The mobility can be attributed to special features of building production in the construction of real estate due to the ability of its elements to move over long distances in certain directions, to be combined in the place of a construction site in the form of facilities, the rational functioning under specific conditions with a capacity that is sufficient to ensure obtaining finished product at a predetermined time. A distinctive feature of the mobility of construction production, compared with other types of productions, is that the building object is always in the immovable state, and all the instruments of production and living labor, in a predetermined order periodically are delivered in the construction area.
\end{abstract}

\section{Introduction}

Mobility of the construction system can be shown in its two states: in the movement and concentration of its elements to the any particular period of time, and in the form of all the time changing, of its capacities and its functioning [1-6]. Therefore, the construction system is regarded as a complete organizational system with variable parameters, which are provided by the mobility of its elements that are located at the any distance from the stationary based zones of production and non-production areas, with the presence of the main, auxiliary and service processes. In these contentious interlinkages, need to find such combination thereof, which would be reached, its minimum value of production costs

\section{Organization and management of mobility of building production}

Mobility of construction production is characterized by the following features of their phases with their specific fluctuations during the development process, changing in compositions and structures (Table. 1). In the mobility of construction processes can be divided into three phases of their development:

\footnotetext{
${ }^{*}$ Corresponding author: onib@mail.ru
} 


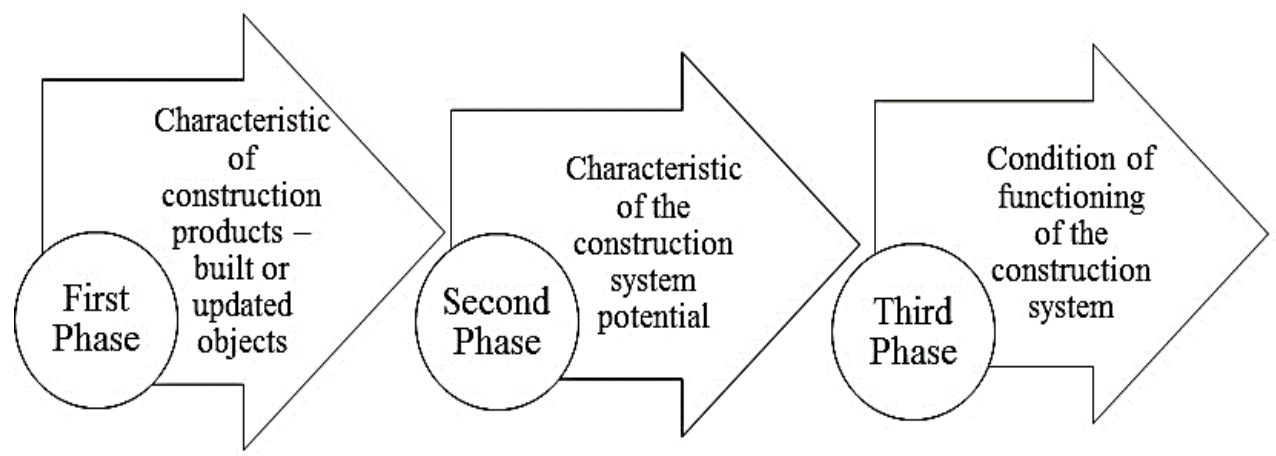

Fig. 1. Characteristics of the mobility parameters within the phases of construction production.

- Phase 1 is characterized by indicators of construction products (object of construction, the structure of construction and assembly works, the timing and sequence of their execution, etc.) and the infrastructure indicators of construction.

- $\quad$ Phase 2 associated with the movement and concentration of elements of construction production within their infrastructures.

- Phase 3 includes indicators of the labor movement, machines and construction elements within the construction streams when receiving the finished construction products.

At the first phase of formation of the mobility phases of construction production seek to find its rational parameters, the conjunction of their characteristics, and at the third phase the conjunction of the system of resources, machines and structures.

In order to achieve a more efficient mobility of construction production, it is recommended to analyze the phases on the following parameters:

\section{Phase 1}

- formation of characteristics of construction products;

- classification of space-planning and constructive decisions of building objects;

- the selection of fabrication processes of constructions and products;

- determining the transportation processes of constructions and products;

- calculation of process of the assembly of constructions and products;

- classification and characterization of technological kits;

- assessment of blockiness objects in mobility conditions;

\section{Phase 2}

- peculiarities of the material and technological support of building units under condition of the construction mobility

- rational interaction of fixed and mobile production bases;

- ways of increasing specialization of production bases;

- structure and equipment of production bases;

- peculiarities of infrastructures during the construction of building projects;

- peculiarities of action of social units;

- site layout characteristics for mobile method of assembling of construction objects

Phase 3

- determining characteristic features of the construction systems when moving structural elements and functioning of the streams of construction on construction site;

- calculation of volumes of production of construction works;

- choice of specialization intensity, concentration of construction assembly work at the construction site;

- calculation of the degree of mobility construction streams in accordance with their rationality, organization (level of providing conjunction of works in space and time) 
equipment the streams by technique (using the comprehensive mechanization, automation of work, etc.)

Development of building systems management schemes according with the parameters of processes of development and their effectiveness;

Obtaining of schemes providing human resources processes with regard to the ways of their movement and concentration

Under the influence of changes in the degree of mobility of construction production, also its potential is changing as a combination of readiness indicators of construction streams Cr's, Crs, social readiness $\mathrm{Csr}$, technical readiness $\mathrm{Ctr}$, provision readiness $\mathrm{Cpr}$, readiness of transported bases tpc, construction infrastructure inventory tpc, et al. (Fig. 1).

Following the development of character and construction production structures it is possible to move on to assess the effectiveness of its degree of mobility as a cumulative effect of accounting in phases to their development and transformation (Table 2). To assess the effectiveness ofmobile production of construction taking into account its changes in output by phases is used:

- An integrated approach combining the total state of development of the construction phases by their coefficients of readiness Crd', Crd", Crd'", of phaseMpi and the total capacity of Mpi; (Table 2)

- A dynamic approach is determining the nature of the effects of the changes on the life cycle of the construction of Pi of real estate objects Ii influenced by changes in readiness coefficient Crei system capacity Mi (original transformed Ii).

- By the total equality of the effects of cost-benefit

Table 2. Transformation of production capacity Mp, taking into account the mobility of construction production on the phases of the construction cycle.

\begin{tabular}{|c|c|c|c|c|c|c|c|}
\hline 壳 & 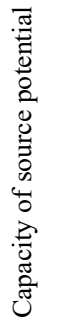 & 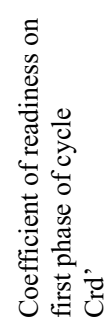 & 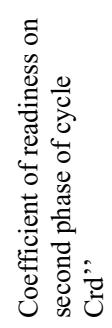 & 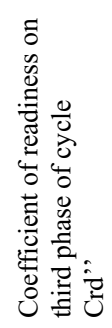 & 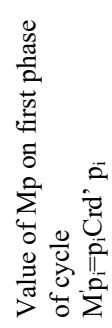 & 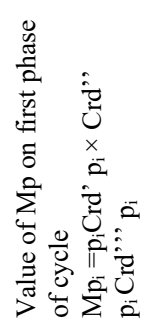 & 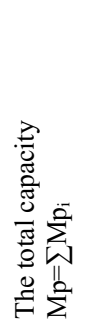 \\
\hline First & $\begin{array}{l}8000 \\
5000 \\
6000 \\
4000\end{array}$ & $\begin{array}{l}0,86 \\
0,86 \\
0,86 \\
0,86\end{array}$ & $\begin{array}{l}0,8 \\
0,8 \\
0,8 \\
0,8\end{array}$ & $\begin{array}{l}0,93 \\
0,93 \\
0,93 \\
0,93\end{array}$ & $\begin{array}{l}5500 \\
3440 \\
4130 \\
2750\end{array}$ & $\begin{array}{l}5115 \\
3199 \\
3840 \\
2557\end{array}$ & 1411 \\
\hline Second & $\begin{array}{l}8000 \\
5000 \\
6000 \\
4000\end{array}$ & $\begin{array}{l}0,67 \\
0,67 \\
0,67 \\
0,67\end{array}$ & $\begin{array}{l}0,8 \\
0,8 \\
0,8 \\
0,8\end{array}$ & $\begin{array}{l}0,93 \\
0,93 \\
0,93 \\
0,93\end{array}$ & $\begin{array}{l}4290 \\
2680 \\
3220 \\
2140\end{array}$ & $\begin{array}{l}3989 \\
2492 \\
2994 \\
1990\end{array}$ & 11465 \\
\hline Third & $\begin{array}{l}8000 \\
5000 \\
6000\end{array}$ & $\begin{array}{l}0,67 \\
0,67 \\
0,67\end{array}$ & $\begin{array}{l}0,8 \\
0,8 \\
0,8\end{array}$ & $\begin{array}{l}0,93 \\
0,93 \\
0,93\end{array}$ & $\begin{array}{l}4290 \\
2680 \\
4130\end{array}$ & $\begin{array}{l}3989 \\
2492 \\
3840\end{array}$ & 12897 \\
\hline
\end{tabular}

\section{Conclusions}

At the heart of building production in the vast, majority of cases, there is object of real estate attached territorially. In the process of its construction, to a particular area is moved in a 
certain sequence, technical, human, large-scale resources and infrastructures. Precisely these features of the construction production are different of many other productive sectors:

- non stationarity, temporary nature, inhomogeneity, relatability;

- adaptability to technological linkages of binding site and the nature of real estate objects;

- instability of the technological interlinkages;

- simultaneity involvement in the production of relevant technologies and companies;

- a variety of building objects;

- mobility of technological processes;

To reconcile these attributes in integrating and systemically important features of mobility with their organizing, economic, technological, technical control peculiarities should be still at the stage of preparation of the construction, to determine their effective parameters.

The practice of using rational mobility of construction processes shows that the duration of the construction of real estate objects (their life cycle of production) can be reduced by 18 $20 \%$ and to achieve by this the reduction in cost of construction and installation works at 12 $15 \%$.

\section{References}

1. V.I. Korobko, Environmental management

2. V.Y. Ostashko, Lifecycle Management business investment and construction of the complex: theory and practice

3. V.M. Serov, N.A. Nesterova, A.V. Serov, Organization and Management in Construction

4. P.G. Grabovoy, Economics and Property Management

5. A.D. Sheremet, E.V. Negashev, Methods of financial analysis

6. N.A. Shitukhina, The theory of the organization of building production 